1 Hallet M, Tandon D, Berardelli A. Treatment of peripheral neuropathies. $J$ Neurol Neurosurg peripheral neuropathies. J Neur
Psychiatry 1985;48:1193-207.

2 Conn DL, Dyck PJ. Angiopathic neuropathy in connective tissue diseases. In: Dyck PJ, Thomas PK, Lambert EH, Bunge R, eds Peripheral Neuropathy Vol 2, 2nd ed. Philadelphia, London: WB Saunders, 1984:2027-43.

3 Dyck PJ, Benstead TJ, Conn DL, Stevens JC Wyndebank AJ, Low PA. Nonsystemic vasculitic neuropathy. Brain 1987;110:843-54.

4 Hughes RAC Cameron JS, Hall SM, Heaton J, Payan J, Teoh R. Multiple mononeuropathy as the initial presentation of systemic lupus erythematosus; nerve biopsy and response to plasma exchange. J Neurol $1982 ; 228: 239-47$.

5 Feasby TE, Gilbert JJ, Brown WF, Hahn AF, Koopman WF, Zochodne DW. An acute axonal form of Guillain-Barre syndrome. Brain 1986;109:1115-26.

\begin{abstract}
Are alpha-1-antichymotrypsin and inter-alpha-trypsin inhibitor peripheral markers of Alzheimer's disease?
\end{abstract}

The definite diagnosis of Alzheimer's disease (AD) requires both clinical criteria of probable $\mathrm{AD}$ and neuropathological evidence of $\mathrm{AD}$ lesions. ${ }^{1}$ At present there is no laboratory test for a premortem diagnosis. Recently, genetic and histochemical studies identified protease inhibitors as components that might be implicated in the formation of the amyloid substance in $\mathrm{AD}$ brains. First, Abraham et al $^{2}$ suggested a potential role of alpha-1-antichymotrypsin (ACT) in the pathogenesis of the lesions, moreover Matsubara et $a l^{3}$ found an increased serum concentration of ACT in AD. Second, several authors ${ }^{4-6}$ showed that one transcript of A4 amyloid precursor contained an additional sequence similar to the active site of inter-alpha-trypsin inhibitor (ITI). The purpose of our study was to test the diagnostic value of ACT and ITI in serum and CSF from $A D$ patients.

Sera and CSF were collected from eight men and 16 women with probable $A D,{ }^{1}$ mean (SD) age $66(9.8)$ years, and from a control group of 19 men and six women aged $64(8 \cdot 3)$ years. Controls were volunteers free of any neurological disease, with a MMS score higher than 28 , who had had a myelo or radiculography for proven disk herniation. CSF was not collected especially for this study. The procedure was approved by the ethical committee of Lille. ACT and ITI contents were measured by electroimmunodiffusion methods. Semi-quantitative determination was used for ITI in CSF because of its low concentration. Statistical assessment used non parametric tests (Mann and Whitney's U test and Spearman's rank correlation test).
In the control subjects there were 1) no difference in serum or CSF ACT and IT contents between males and females, 2) no correlation between age and both serum ITI and CSF ACT contents, 3) a positive correlation between serum ACT contents and age $(\mathrm{p}<0.02)$.

Between $A D$ patients and controls, there were no difference in serum or CSF ACT and ITI contents, and no difference of the ACT $\mathrm{CSF} /$ serum ratio (table).

In $\mathrm{AD}$ patients there was no correlation between the severity of dementia on MMS and Blessed scores and serum or CSF ACT contents, and a negative correlation between MMS and Blessed B scores and serum ITI contents $(p<0.05)$.

Our results show that ACT and ITI are not useful markers of $\mathrm{AD}$ in serum and CSF. They don't confirm those of Matsubara et al. The ACT CSF/serum ratio was not significantly modified in $\mathrm{AD}$ patients, which is consistent with the hypothesis that the bloodbrain barrier is not strongly affected in this disease. The correlation between serum ITI contents and the severity of the dementia could be explained by non specific metabolic disturbances.

$$
\begin{array}{r}
\text { ALAIN FURBY } \\
\text { DIDIER LEYS } \\
\text { ANDRE DELACOURTE } \\
\text { LUC BUEE } \\
\text { GUIDO SOETAERT } \\
\text { HENRI PETIT } \\
\text { Departments of Neurology and Neurosciences, } \\
\text { INSERM U156 and ADERMA, } \\
\text { CHRU de LILLE, Hopital B, } \\
59037 \text { Lille, France }
\end{array}
$$

1 McKhann G, Drachman D, Folstein M, Katzman R, Price D, Stadlan EM. Clinical diagnosis of Alzheimer's disease: Report of the NINCDS-ADRDA work group under the auspices of Department of Health and Human Services Task Force on Alz
Neurology 1984;34:939-44.

2 Abraham CR, Selkoe DJ, Potter H. Immunochemical identification of the serine protease inhibitor alpha-1-Antichymotrypsin in the inhibitor alpha-1-Antichymotrypsin in the brain amyloid deposits

3 Matsubara E, Amari M, Shoji M, et al. Serum concentration of Alpha-1-antichymotrypsin is elevated in patients with senile dementia of the Alzheimer type. Progress in clinical and biological research 1989;317:707-14.

4 Ponte $\mathrm{P}$, Gonzalez-Dewhitt $\mathrm{P}$, Schilling J, et al. A new A4 amyloid mRNA contains a domain homologous to serine proteinase inhibitors. Nature 1988;331:525-7.

5 Kitaguchi N, Takahashi Y, Tokushima Y, Shiojiri S, Ito H. Novel precursor of Alzheimer's disease amyloid protein shows protease inhibitory activity. Nature 1988; 331:530-2.

6 Tanzi RE, McClatchey AI, Lamperti ED, Villakomaroff L, Gusella JF, Neve RL. Protease komaroff L, Gusella JF, Neve RL. Protease
inhibitor domain encoded by an amyloid protein precursor mRNA associated with Alzprotein precursor mRNA associated with Alz-
heimer's disease. Nature 1988;331:528-30.
Postradiation motor neuron syndrome of the upper cervical region-a manifestation of the combined effect of cranial irradiation and intrathecal chemotherapy?

CNS prophylaxis is now an integral part of the treatment of acute leukaemia. We wish to report an unusual case of neurogenic amyotrophy apparently resulting from damage to the anterior horn cells of the upper cervical cord and lower brainstem during cranial irradiation.

The patient presented at the age of 13 in January 1977 with T-cell acute lymphoblastic leukaemia and was treated according to the United Kingdom Acute Lymphoblastic Leukaemia Trial 4 (UKALL 4) (intensive) schedule. This comprised induction with cyclophosphamide, cytosine arabinoside (ara-C), vincristine, prednisolone and intrathecal ara-C; consolidation with the same, together with adriamycin, asparaginase, 6-mercaptopurine, intrathecal methotrexate and cranial irradiation; and maintenance with vincristine, methotrexate, ara-C, 6-mercaptopurine and prednisolone. The total dose of irradiation was $2400 \mathrm{cGy}$ (rads) and the field extended to the level of the C3 vertebral body.

Apart from an early bone marrow relapse in June 1977 , he made a complete recovery. In particular, there was no evidence of CNS involvement at any time.

He received his last dose of vincristine in May 1979 and completed his chemotherapy by June 1979 . The period of cranial irradiation spanned 19 days in April 1977.

In January 1981 he was referred to the neurology clinicwith a three month history of progressive painless wasting and weakness of the shoulder girdle muscles. There was marked bilateral winging of the scapulae, left worse than right. The trapezii, rhomboids, supra- and infraspinati, deltoids, teres major and both sternocostal and clavicular heads of the pectoralis major muscles were wasted, more on the left, and power was reduced to grade 4 on the left and $4+$ on the right. There was minimal weakness of the left biceps. The triceps muscles were spared as were the distal upper limb muscles and lower limbs. There was questionable weakness of the orbicularis oculi and failure of frontalis to maintain elevation of the eyebrows. Although his face was thin there was no focal wasting or demonstrable weakness of the other facial muscles. There were no sensory symptoms or signs. Tendon reflexes were well preserved and symmetrical. Plantar responses were flexor.

Investigations at this stage including muscle enzymes, thyroid function, cervical spine radiographs, haematological screen and bone marrow were normal. Electromyographic (EMG) studies revealed reduced amplitude ulnar sensory nerve action potentials and evidence of chronic partial denervation of both deltoids, more on the left.

Thereafter the condition appeared to arrest with no objective progression noted during eight years of follow up (1981-9). Serial EMGs showed evidence of chronic partial denervation and reinnervation in the brachioradialis, biceps, deltoids, supraspinatus and trapezius muscles without pathological activity at rest. No significant abnormality was demonstrated in the quadriceps. In the right tibialis anterior a full interference

\begin{tabular}{|c|c|c|c|}
\hline & & Controls group & AD Patients \\
\hline $\begin{array}{l}\text { ACT mean }(S D) \\
\text { ITI mean }(S D)\end{array}$ & $\begin{array}{l}\text { Serum } \\
\text { CSF } \\
\text { Serum/CSF } \\
\text { Serum }\end{array}$ & $\begin{array}{c}0.67(0.27) \mathrm{g} / 1 \\
6.97(1.45) \mathrm{mg} / 1 \\
11.46(4.5) \\
0.71(0.19) \mathrm{g} / 1\end{array}$ & $\begin{array}{c}0.63(0.22) \mathrm{g} / 1 \\
7.34(0.66) \mathrm{mg} / 1 \\
12.14(4.53) \\
0.72(0.29) \mathrm{g} / 1\end{array}$ \\
\hline
\end{tabular}
pattern contained occasional polyphasic units of normal amplitude and duration which were not felt to be of clinical significance. Muscles
Table Serum Alpha-1-antichymotrypsin (ACT) and Inter-alpha-trypsin inhibitor (ITI) contents, $C S F A C T$ contents and $A C T$ serum/CSF ratio in controls group and Alzheimer's disease (AD) patients. 
sampled serially showed little change with time.

Nerve conduction studies showed norma motor latencies, conduction velocities and $F$ wave latencies. The ulnar sensory nerve action potentials and mixed afferent nerve potentials were of reduced amplitude but also had normal conduction times, suggesting an axonal degeneration.

A biopsy of the deltoid and quadriceps muscles showed non-specific changes only and no dystrophic features.

In February 1989 an MRI scan of the cervical spine showed the upper cervical cord to have a slightly increased signal intensity on the T2 weighted spin echo sequence, the significance of which was unclear.

This patient developed an asymmetrical and patchy wasting and weakness of the shoulder girdle muscles involving several myotomes from $\mathrm{C} 3$ to $\mathrm{C} 7$. The explanation for the symptomless minimal weakness of the orbicularis oculi and frontalis muscles is uncertain. It may reflect patchy involvement of the brainstem (similar symptomless involvement of the other cranial nerves such as the bulbar muscles would escape detection) or might merely be constitutional.

We postulate that the neurological abnormalities in our patient are a manifestation of augmentation of irradiation by combination intrathecal and systemic chemotherapy with two potentially neurotoxic agents, methotrexate and cytosine arabinoside, in accordance with the intensive UKALL 4 regimen. The predominant features of this case are in keeping with a postradiation motor neuron syndrome.' The minor ulnar sensory abnormalities detectable only on EMG and without associated clinical symptoms or signs were probably secondary to vincristine.

Four types of radiation myelopathy have been described, ${ }^{2}$ the least common being lower motor neuron syndrome. The mechanism underlying this phenomenon is unclear but there is evidence from clinical and pathological studies that radiation injury to vascular endothelium produces ischaemia which leads to selective anterior horn cell degeneration. ${ }^{3-5}$ Greenfield and Stark observed this phenomenon in three patients, and Sadowsky et al reported it in a fourth. ${ }^{16}$ All four cases consisted of a selective lower motor neuron disease confined to lower limb muscles starting three to eight months after radiation of the spinal axis. All followed a subacute and selflimiting course. In our patient the latent period was longer ( $21 / 2$ years), in keeping with other studies where the average symptom free interval was 14 months, ${ }^{2}$ but otherwise the disease followed a similar course. Unlike the other cases described, he did not receive direct irradiation to the spinal cord apart from that part of the upper cervical cord included in the field during cranial irradiation.

Byfield described an infant who developed radiation myelitis of the cervical cord after receiving routine doses of vincristine and radiation therapy and postulated a synergistic effect. ${ }^{7}$ In 1975 a histopathological study by Price et al suggested a similar synergism between irradiation and intravenous methotrexate in the development of fatal leukoencephalopathy in children with ALL. ${ }^{8}$ Intrathecal methotrexate has a direct neurotoxic effect ranging from a chemical arachnoiditis to transient/permanent paresis and encephalopathy.

Cytosine arabinoside, the other intrathecal agent used in our patient, can cause disseminated multifocal coagulation necrosis of white matter and has been implicated in enhancing radiation induced chromosomal abnormalities.' A recent study has shown that intrathecal ara-C significantly reduces the isoeffect doses required for the development of radiation damage in rat spinal cord. ${ }^{10}$

We are not aware of any previous reports describing an upper cervical cord motor neuron syndrome occurring following cranial rradiation and would be interested to hear if others have encountered this feature in leukaemic patients treated similarly.

SV TAN Leicester Royal Infirmary,
Leicester, UK

Figure CT scan shows thickened retrobulbar low attenuation in the thickened portion.

Correspondence to: $\mathrm{Dr}$ Tan, 21 Avon Road Leicester LE3 $3 \mathrm{AB}$, UK

1 Sadowsky CH, Sachs E, Ochoa J. Postradiation motor neurone syndrome. Arch Neurol 1976; 33:786-7.

2 Reagan TJ, Thomas JE, Colby MY. Chronic progressive radiation myelopathy. JAM 1968;203(2): 128-32.

3 Jellinger K, Sturm KW. Delayed radiation myelopathy in man. $J$ Neurol Sci 1971;14: 389-408.

4 Palmer JJ. Radiation myelopathy. Brain 1972; 95:109-22.

5 Dodson WE, Landau WM. Motor neurone loss due to aortic clamping in repair of coarctation. Neurology 1973;23:539-42.

6 Greenfield MM, Stark FM. Post-irradiation neuropathy. Am $J$ Roentgenol Radium Ther Nucl Med 1948;60:617-22.

7 Byfield JE. Ionising radiation and vincristine: possible neurotoxic synergism. Radiol Clin Biol 1972;41:129-38.

8 Price JA, Jamieson PA. The Nervous System in childhood leukaemia II. Subacute leukoencephalopathy. Cancer 1975;35:306.

9 Ejima Y, et al. Enhanced expression of X-ray and $U V$-induced chromosome aberrations by cytosine arabinoside in ataxia telangiectasia cells. Mutat Res 1986;159(1-2):117-23.

10 Van der Kogel AJ, Sissingh HA. Effects of intrathecal methotrexate and cytosine arabinoside on radiation tolerance of the rat spinal cord. Radiother Oncol 1985;4(3): 239-51.

\section{Optic nerve cysticercosis: a case report}

Cysticercosis is caused by infection from the larval form of Taenia solium and humans are an intermediate host. The subcutaneous tissue, brain, eye, muscle, heart, liver and peritoneum are common sites of encystment. In the eye, the conjuctiva is the most common site. Subretinal and intravitreal locations have also been described. ${ }^{2}$ Cysticercosis of the intracranial portion of the optic nerve is rare.

A 15 year old school girl presented with deteriorating vision in her right eye which had progressed over a seven month period. There was no history of pain or inflammation in the eye, trauma, headache, vomiting, seizures, or tuberculosis. General physical and systemic examinations were normal There was no subcutaneous nodule or cafeau-lait spots. Neurological examination was also normal except for the patient's inability to count fingers at less than $30 \mathrm{~cm}$ with the right eye. The pupils were equal and reacting. Fundus oculi examination revealed disc pallor in the upper half, disc margins elevated in the lower part and neighbouring retina for an area of two dioptres below the disc. Vessels and macula were normal. Pigmentary changes were present. The tension was $17.3 \mathrm{~mm}$ in both eyes. Other cranial nerves were normal. The rest of the neurological examination did not reveal any abnormality. segment of right optic nerve with small area of

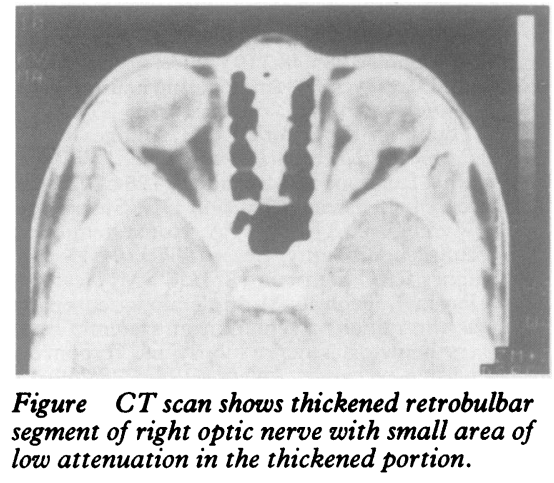
meters were normal. The erythrocyte sedimentation (ESR) was $26 \mathrm{~mm}$ and the VDRL was negative. Skull radiographs of the optic foramen and superior orbital fissures were normal. CT scan of the head and orbit with contrast enhancement showed a retrobulbar segment of the right optic nerve thickened with a small area of low attenuation in the thickened portion of the optic nerve Retrobulbar fat was preserved and the muscle cone was normal. The optic nerve at the orbital apex appeared to be of normal width. The brain parenchyma was normal as was the left optic nerve (fig). Perimetry revealed superior altitudinous right hemianopia Ultrasonography showed a mass in the region of the right optic nerve. The Casoni test was negative.

A diagnosis of optic nerve glioma or granuloma was considered. A right frontal craniotomy and extradural frontal orbitomy was performed. After incising the tenon's fascia normal retrobulbar fat protruded. The optic nerve was exposed by microdissection and was found to have fusiform thickening. A small portion of nerve just behind the optic globe was normal as was nerve near the apex. Longitudinal incision was made over the maximum bulge. There was intense fibrosis On deeper incision a sago grain like cyst was found and excised. Histopathology revealed it to be cysticercosis. Postoperatively the patient's vision fully recovered but there was IIIrd nerve paresis.

Cysticercosis is one of the most serious countries. ${ }^{3}$ Any part of the neuraxis can be involved, except the peripheral nerves, resulting in protean features. ${ }^{4}$ Ocular cysticercosis occurs in 3\% of cases and may be single, unilateral or bilateral. ${ }^{5}$ Subretinal involvement of the eye usually occurs initially through the posterior ciliary arteries but migration of the parasite is common. The nasal side of the eye is more commonly involved than the lateral side. This is due to an anatomical peculiarity of the ophthalmic artery which after giving rise the lacrimal branch runs along the medial side of the orbit and divides into its terminal branches. ${ }^{2}$ The branch of the central artery of the retina and retinal blood vessels may thus be involved.

The usual symptoms are of pain, irritation of the eyes due to iridocyclitis and dimness of vision. The eye may be involved alone or may be associated with other clinical features of neuro-cysticerosis when the brain is also involved.

Optic nerve involvement is rare in any kind of cyst or granuloma. As a result, in our public health problems in the developing optic nerve obtains its blood supply from the 